\title{
Effects of low dose oral contraceptives on very low density and low density lipoprotein metabolism.
}

\section{Citation}

Walsh, B W, and F M Sacks. 1993. "Effects of Low Dose Oral Contraceptives on Very Low Density and Low Density Lipoprotein Metabolism." Journal of Clinical Investigation 91 (5) (May 1): 21262132. doi:10.1172/jci116437.

\section{Published Version}

doi:10.1172/JCI116437

\section{Permanent link}

http://nrs.harvard.edu/urn-3:HUL.InstRepos:30205339

\section{Terms of Use}

This article was downloaded from Harvard University's DASH repository, and is made available under the terms and conditions applicable to Other Posted Material, as set forth at http:// nrs.harvard.edu/urn-3:HUL.InstRepos:dash.current.terms-of-use\#LAA

\section{Share Your Story}

The Harvard community has made this article openly available.

Please share how this access benefits you. Submit a story.

\section{Accessibility}




\title{
Effects of Low Dose Oral Contraceptives on Very Low Density and Low Density Lipoprotein Metabolism
}

\author{
Brian W. Walsh ** and Frank M. Sacks * \\ ${ }^{*}$ Channing Laboratory, Department of Medicine; ${ }^{\ddagger}$ Department of Gynecology; and the Clinical Research Center, \\ Brigham and Women's Hospital and Harvard Medical School, Boston, Massachusetts 02115
}

\begin{abstract}
Oral contraceptives $(O C)$ raise plasma triglyceride and VLDL levels, which may be of concern, since some conditions characterized by elevated triglycerides are associated with atherosclerosis. To identify the responsible mechanism, we studied 11 healthy premenopausal women, 5 of whom were taking $\mathrm{OC}$ containing 0.035 mg ethinyl estradiol, and 6 of whom were not. Their rates of VLDL and LDL metabolism were measured by endogenously labeling apoB, the protein component of VLDL and LDL, by an intravenous infusion of deuterated leucine. $O C$ use had the greatest effect on the large, triglyceride-rich VLDL subfraction (Sf 60-400), increasing plasma levels threefold and production rates fivefold $(P<0.05)$. Among $O C$ users, small VLDL (Sf 20-60) levels were 2.2 times higher, and production rates were 3.4 -fold higher $(P<0.05)$. The fractional catabolic rates of large and small VLDL were similar among OC users and nonusers. LDL levels and metabolic rates were not significantly different between the two groups. Thus, contemporary low dose OC substantially raise VLDL levels by increasing the production rate of large, triglyceride-rich VLDL, and not by slowing VLDL catabolism. Since VLDL catabolism is not impaired, we speculate that the hypertriglyceridemia induced by $\mathrm{OC}$ may be less atherogenic than that of hypertriglyceridemia resulting from impaired lipolysis. This may explain why long-term OC use does not appear to promote atherosclerosis. (J. Clin. Invest. 1993. 91:2126-2132.) Key words: estrogen • cholesterol • triglyceride • apolipoprotein B • hormones
\end{abstract}

\section{Introduction}

Women who use oral contraceptives $(\mathrm{OC})^{1}$ have higher levels of plasma triglycerides, the majority of which are carried by VLDL. The estrogen component of OC is believed to be responsible for this effect, and appears to raise triglyceride levels in a dose-dependent manner (1). This increase in triglycerides may be of concern, since some conditions characterized by elevated

Address correspondence to Dr. Brian W. Walsh, Department of Obstetrics and Gynecology, Brigham \& Women's Hospital, 75 Francis Street, Boston, MA 02115.

Received for publication 6 August 1991 and in revised form 1 October 1992

1. Abbreviations used in this paper: $\mathrm{D}_{3}$, trideuterated leucine; FCR, fractional catabolic rate; $\mathrm{OC}$, oral contraceptives; Sf, Svedberg units of flotation.

J. Clin. Invest.

(C) The American Society for Clinical Investigation, Inc. 0021-9738/93/05/2126/07 \$2.00

Volume 91, May 1993, 2126-2132 triglycerides are associated with atherosclerosis (2). However, the development of atherosclerosis may not be due to the elevated triglycerides per se, but may depend upon the nature of the primary metabolic derangement which caused the high triglyceride levels to occur. For instance, hypertriglyceridemia resulting from increased VLDL synthesis may be less harmful than that resulting from impaired VLDL catabolism. This is supported by the observations that postmenopausal estrogen replacement (3), moderate alcohol consumption (4), and cholestyramine, a bile acid sequestering resin (5), all of which raise triglycerides by increasing VLDL synthesis, have not been found to promote atherosclerosis and in fact appear to lower the risk of coronary heart disease (6-8). In contrast, endogenous hypertriglyceridemia, in which VLDL levels rise principally due to impaired catabolism of VLDL (9), has been associated with cardiovascular disease (10). The lipoprotein abnormalities that result from impaired VLDL catabolism may be the factors which are atherogenic, such as the cholesterol ester enrichment of VLDL, or the reduced levels of HDL.

Since millions of women currently use OC it is important to delineate the metabolic alterations responsible for the elevation of triglycerides. Prior work evaluated very high dose $\mathrm{OC}$ which are uncommonly used today; one study found $\mathrm{OC}$ to both increase triglyceride synthesis as well as impair triglyceride clearance (11), whereas another study found OC to increase VLDL apoB production only (12). Furthermore, these studies did not evaluate the effect of OC on different subpopulations of VLDL particles, which may be important, since VLDL consists of a heterogenous spectrum of particles with varying triglyceride content and, perhaps, different atherogenicity $(13,14)$. There has been no work evaluating the effect of OC on LDL metabolism. We therefore studied the metabolism of individual VLDL subfractions and of LDL in nonusers and users of contemporary low dose OC's, to identify the mechanisms by which $O C$ use raises plasma VLDL and triglyceride levels. The rates of VLDL and LDL synthesis and catabolism were measured by endogenous labeling of their primary protein component, apoB, with a nonradioactive amino acid tracer, trideuterated leucine $\left(\mathrm{D}_{3}\right.$-leucine $)$.

\section{Methods}

Subjects. 11 healthy premenopausal women, ages 22-27, were enrolled into this study. Nine were dieticians, and two were research associates. The first six subjects (three OC users, and three nonusers) had been randomly selected to participate in a pilot study of lipoprotein metabolism. After marked differences in VLDL metabolism were noted between the $\mathrm{OC}$ users and nonusers, an additional five subjects (two $\mathrm{OC}$ users and three nonusers) were recruited to complete the final study group. The five $O C$ users had all taken oral contraceptives containing $0.035 \mathrm{mg}$ ethinyl estradiol for more than $1 \mathrm{y}$. Four of the five OC users took oral contraceptives containing norethindrone, given as $1 \mathrm{mg}$ daily for $21 \mathrm{~d}$ (Ortho-Novum 1/35; Ortho Pharmaceutical Corp., Raritan, 
$\mathrm{NJ}$ ) for subjects 1 and 4 ; or given as $0.5 \mathrm{mg}, 0.75 \mathrm{mg}$, and $1.0 \mathrm{mg}$ given sequentially for $7 \mathrm{~d}$ each (Ortho-Novum 777; Ortho Pharmaceutical) for subjects 2 and 3 . The fifth OC user took an OC containing ethynodiol diacetate, given as $1 \mathrm{mg}$ daily for $21 \mathrm{~d}$ (Demulen; Searle Pharmaceuticals Inc., Skokie, IL) for subject 5 . The other six subjects (6-11) were not taking $O C$ and had regular menstrual cycles. No subjects used any other prescription drugs or tobacco, nor consumed more than $15 \mathrm{~g}$ of ethanol daily. The composition of their usual diet was analyzed by a semiquantitative food frequency questionnaire (15). Subjects recorded the duration of exercise performed over one month's time. Subjects gave informed consent, and the study was approved by the Committee for the Protection of Human Subjects at Brigham and Women's Hospital. All 11 subjects completed the entire study.

Protocol. The subjects were admitted to the Clinical Research Center at Brigham and Women's Hospital, after a 12-h overnight fast. The metabolism of VLDL subfractions and of LDL was studied once in all 11 subjects. The first six subjects were studied twice $28 \mathrm{~d}$ apart, to determine measurement reproducibility: LDL and unfractionated VLDL metabolic rates were measured during the first admission, and LDL and VLDL subfractions were measured during the second admission. They maintained their usual diet and exercise patterns between admissions. They recorded all foods eaten during the $24 \mathrm{~h}$ before the first admission and replicated this diet the day before the second admission. OC users were studied during the same day of their monthly oral contraceptive cycle; nonusers, during the same day of their natural menstrual cycle. The subsequent five subjects were admitted only once.

During each admission, the metabolism of LDL and VLDL was evaluated by endogenously labeling their primary protein component, apoB, by a constant $16-\mathrm{h}$ intravenous infusion of a nonradioactive isotope, trideuterated leucine (L-leucine, 5,5,5- $\mathrm{d}_{3}$; Tracer Technologies, Cambridge, MA), delivered at a rate of $4.7 \mu \mathrm{mol} / \mathrm{kg}$ per $\mathrm{h}$ after a priming dose of $4.2 \mu \mathrm{mol} / \mathrm{kg}$. This rapidly achieved and maintained the plasma leucine enrichment at $\sim 4.5 \%$ (Fig. 1). $\mathrm{D}_{3}$-leucine is incorporated by the liver into apoB, which is assembled into VLDL and secreted into the circulation; as VLDL is converted into LDL, the label appears in LDL apoB (Fig. 1). Blood specimens were obtained through a second intravenous catheter in the contralateral arm every 15 minutes for the first $2 \mathrm{~h}$, and hourly thereafter. For the first $4 \mathrm{~h}$, subjects were restricted to noncaloric and noncaffeinated fluids. This was followed by a standardized fat-free and leucine-free diet containing $60 \%$ of the total daily calories required for maintenance, served as lunch (at $4 \mathrm{~h}$ ), dinner (at $10 \mathrm{~h}$ ), and evening snack (at $13 \mathrm{~h}$ ). The diet was leucine free to prevent "dilution" of plasma leucine enrichment by the intake of unlabeled (dietary) leucine. The isotopic enrichment curves of VLDL subfractions and unfractionated VLDL during the fasting period were used to determine their metabolic rates. In this way, the measurement of VLDL metabolism would not be altered by any acute effect of feeding on VLDL production or clearance. Plateau enrichments were unaffected by meals since steady-state enrichment had already been achieved.

Specimen analysis. Blood was collected into tubes containing disodium EDTA, $1.5 \mathrm{mg} / \mathrm{ml}$; aprotinin, $0.01 \mathrm{mg} / \mathrm{ml}$; PMSF, $17.5 \mu \mathrm{g} / \mathrm{ml}$; and gentamicin, $0.05 \mathrm{mg} / \mathrm{ml}$. Blood specimens were then centrifuged to separate plasma. VLDL (density $<1.006 \mathrm{~g} / \mathrm{ml}$ ) was immediately prepared from plasma overlayered with $2 \mathrm{ml} \mathrm{NaCl} 0.9 \%$, and spun in a type 70.1 Ti rotor at 70,000 rpm in an L8-70M instrument (Beckman Instruments, Palo Alto, CA) for $2.5 \mathrm{~h}$. During one of each subject's admissions, VLDL subfractions were prepared from a second aliquot of plasma: large (Svedberg units of flotation [Sf] 60-400) and small (Sf 20-60) VLDL were isolated by cumulative-rate, density-gradient ultracentrifugation (16) using a type $41 \mathrm{SW}$ rotor (Beckman Instruments). LDL (density, $1.019-1.063 \mathrm{~g} / \mathrm{ml}$ ) was isolated by sequential preparative ultracentrifugation at $25,000 \mathrm{rpm}$ for $26 \mathrm{~h}$, in a type 25 rotor (Beckman Instruments) adjusting plasma density with potassium bromide (17). High density lipoprotein was separated from plasma by precipitation after the addition of dextran and magnesium chloride (18). Cholesterol and triglyceride concentrations were determined by enzymatic methods (19) (Boehringer-Mannheim, Indianapolis, IN). ApoB concentrations were measured by a direct ELISA using a polyclonal antibody (obtained from Dr. Peter Herbert, Brown University, Providence, RI) and an alkaline phosphatase conjugate of the same antibody. VLDL-apoB subfraction concentrations, measured by ELISA, were validated by determining the apoB concentrations by gas chromatography/mass spectroscopy (GC/MS) which uses the peak area of leucine from hydrolyzed apoB. Linear regression analysis of ELISA measurements on gas chromatography/mass spectroscopy measurements demonstrates a slope of 0.94 for apoB in large VLDL and 1.04 for apoB in small VLDL. The intraassay coefficients of variation for "blinded" control samples was $1.2 \%$ for cholesterol, $2.7 \%$ for HDL cholesterol, and $6.4 \%$ for apoB.

ApoB was precipitated from fractionated lipoproteins by isopropanol and washed three times $(20)$. We and others $(20,21)$ determined by polyacrylamide gradient gel electrophoresis that the isopropanol precipitate after appropriate washing is free of apoproteins other than apoB. ApoB was hydrolyzed into component amino acids by heating at $120^{\circ} \mathrm{C}$ with $6 \mathrm{~N}$ hydrochloric acid for $16 \mathrm{~h}$. Free amino acids were isolated from plasma by chromatography on AG50W-X8 resin (BioRad Laboratories, Richmond, CA). All amino acids were converted to heptofluorobutyric acid derivatives. The proportion of $\mathrm{D}_{3}$-leucine in each specimen was measured using a 5890 gas chromatograph with a 5988A mass spectrometer (Hewlett Packard, Palo Alto, CA).

Calculation of metabolic rates. The fractional catabolic rate (FCR)

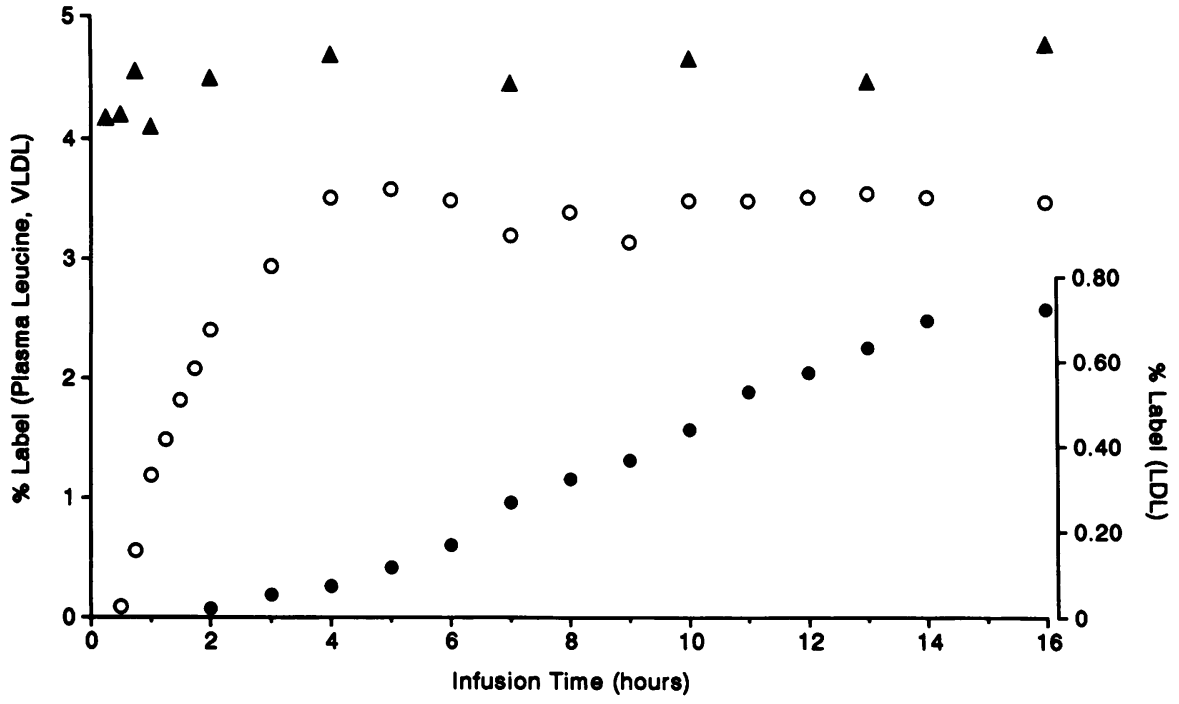

Figure 1. Isotopic enrichment of leucine in plasma (triangles), VLDL apoB (open circles), and LDL apoB (closed circles) during intravenous infusion of trideuterated leucine for subject 2 , study 1 . 


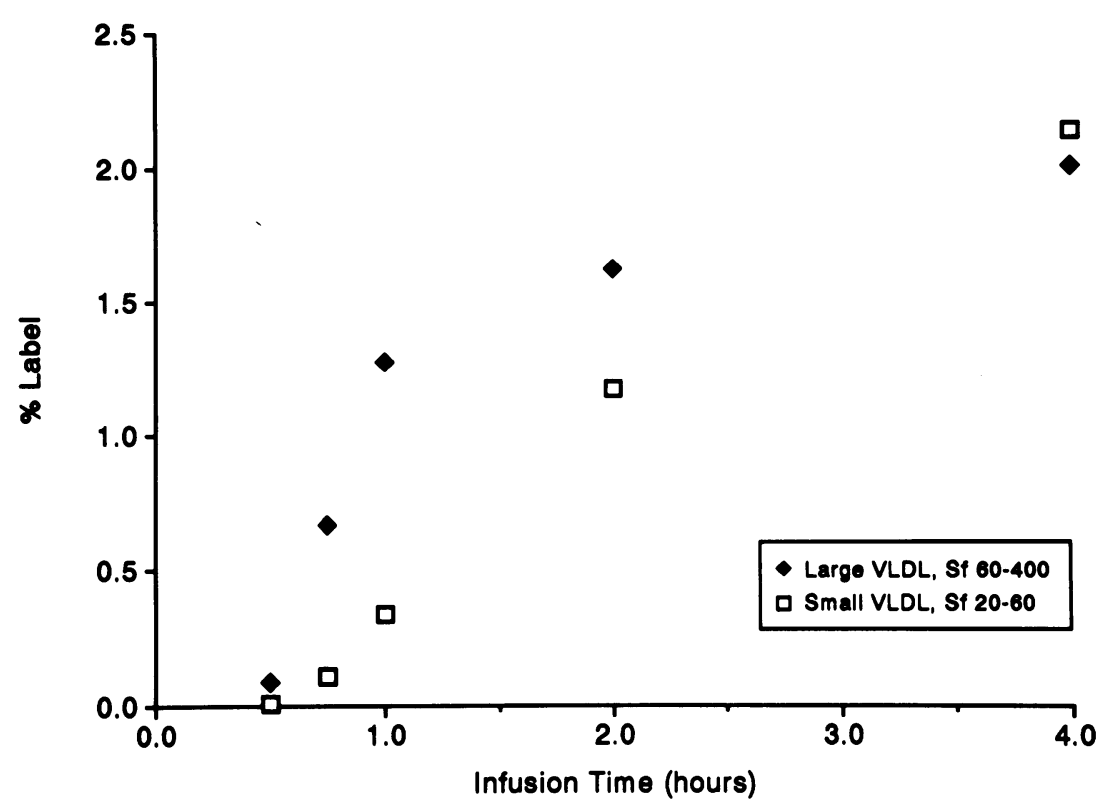

Figure 2. Isotopic enrichment of leucine in large VLDL apoB (Sf 60-400) and small VLDL apoB (Sf 20-60) during intravenous infusion of trideuterated leucine, for subject 2 , study 2 . of LDL was calculated according to the theoretical principle that FCR is equal to the initial rate of appearance of label in a product (LDL apoB) divided by the precursor enrichment (VLDL apoB) if the precursor enrichment is constant (22). This approach was valid for LDL since the enrichment in VLDL-apoB was constant after $5 \mathrm{~h}$ (Fig. 1). This approach could not be used to analyze VLDL subfractions since the initial appearance of label in small VLDL occurs before the enrichment in large VLDL reaches steady state (Fig. 2). We therefore calculated the metabolic parameters of VLDL subfractions by computer modeling using the National Institutes of Health SAAM-30 (simulation, analysis, and modeling) software program. This program uses the rates of appearance of deuterated leucine in apoB of large VLDL and small VLDL, and their plasma pool sizes to calculate metabolic rates. We used a model (Fig. 3), which allowed for: ( $a$ ) secretion into plasma of both large and small VLDL, $(b)$ conversion of large VLDL to small VLDL, $(c)$ clearance of large VLDL independent of conversion to small VLDL, and $(d)$ clearance of small VLDL. ${ }^{2}$ Production rates were calculated as the products of FCR and pool size. Pool size was calculated by multiplying plasma volume (body wt $[\mathrm{kg}]$ times 0.44 ) by plasma concentrations.

Statistical analysis. All VLDL concentrations and production rates underwent logarithmic transformation before statistical analysis to approximately normalize their distributions. Comparisons between mean values in OC users and nonusers were made with Student's unpaired $t$ test (two-tailed with 9 degrees of freedom), after averaging LDL data for the six subjects studied twice. There was no significant time trend in the metabolic data measured in the six subjects who were studied twice.

\section{Results}

Study groups. The OC users and nonusers were similar in terms of age, height, weight, duration of exercise, alcohol consumption, and dietary intake ( Table I). As may be expected for

2. See National Auxiliary Publication Service (NAPS) document No. 04900 for five pages of supplementary material. Order from NAPS \% Microfiche Publications, P. O. Box 3513, Grand Central Station, New York, NY 10163-3513. dieticians, these subjects consumed a diet low in total fat, saturated fat, and sucrose; and high in fiber and complex carbohydrates.

Lipoprotein levels. The mean plasma concentrations of all measured VLDL components (measured during all metabolic studies for each subject) were significantly greater in OC users (Table II): VLDL cholesterol, 1.6 times higher $(P<0.05)$; VLDL triglyceride, 1.7 times higher $(P<0.05)$; and VLDL apoB, 2.4 times higher $(P<0.05)$. Of note is that VLDL in OC users is not enriched in cholesterol or triglyceride; the molar ratio of VLDL cholesterol to VLDL apoB is 4,200 in OC users and is 6,400 in nonusers; the molar ratio of VLDL triglyceride to VLDL apoB is 6,900 in OC users and is 9,800 in nonusers. In addition, each subject had VLDL apoB subfractions measured during one metabolic study, and the higher level of VLDL apoB in OC users was found to be distributed between both VLDL subfractions: large VLDL apoB (Sf 60-400) was 3.0 times higher $(P<0.05)$ and small VLDL apoB (Sf 20-60) was 2.2 times higher $(P<0.05)$ compared to OC nonusers (Table III). The mean plasma concentrations of total cholesterol, HDL cholesterol, LDL cholesterol, and LDL apoB were not significantly different between the two groups.

Reproducibility of metabolic measurements. LDL fractional catabolic rates were highly reproducible when measured twice, 1 mo apart in six subjects: the intraindividual coefficient of variation was only $3.4 \%$. Thus both methodologic and biologic variability is quite low. Methodologic variability may have been minimized by the multiple measurements obtained: LDL FCR is calculated using both $(a)$ the slope of the initial linear appearance of label in LDL, determined from measurements obtained during at least 10 different times; and $(b)$ the precursor (i.e., VLDL) enrichment at plateau, determined by averaging typically 8-10 measurements. The reproducibility of the metabolism of VLDL subfractions was not determined since isolation of VLDL subfractions was performed during only one of each patient's metabolic studies. However, we have previously found that the intraindividual $\mathrm{CV}$ were $35 \%$ and $47 \%$ for large and small VLDL, respectively, in a group of postmenopausal women (3). 


\section{OC USERS}

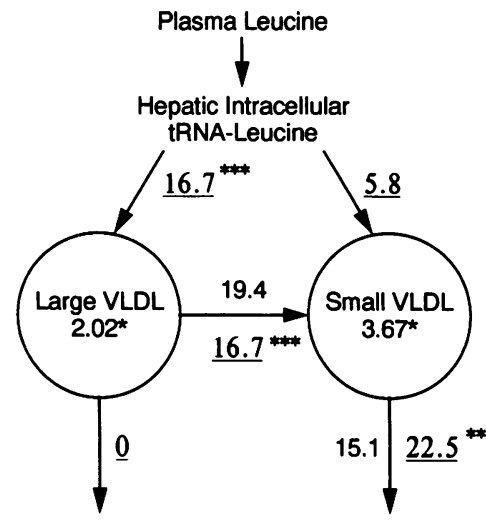

OC NONUSERS

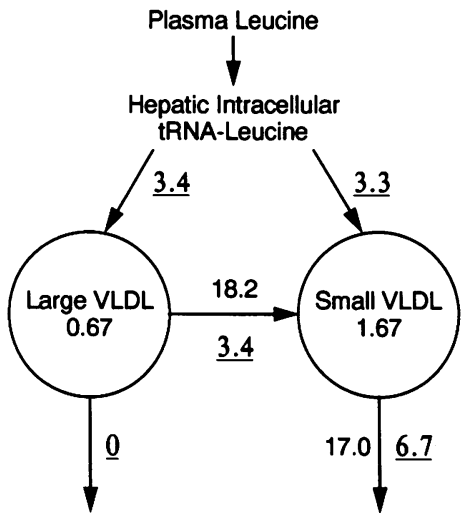

Figure 3. Multicompartmental model used to analyze the appearance of trideuterated leucine infused intravenously as it shifts from the plasma leucine pool, to the intracellular hepatic tRNA leucine pool, the VLDL apoB (Sf 60-400) pool, and/or to the VLDL apoB (Sf 20-60) pool. Numbers inside the circles indicate apoB concentrations ( $\mathrm{nmol} /$ liter); nonunderlined numbers beside arrows are fractional catabolic rates (pool/ d); underlined numbers are absolute production or catabolism rates $(\mathrm{nmol} / \mathrm{kg}$ per d). The figure on the left displays the mean values of the five oral contraceptive users; on the right, the mean values of the six nonusers. Users vs. nonusers, ${ }^{*} P$ $<0.05,{ }^{* *} P<0.01$, and ${ }^{* * *} P<0.005$.
The values for LDL and VLDL metabolic rates of OC nonusers, measured by endogenous stable isotope labeling, are comparable to those obtained in studies by reinfusion of lipoproteins exogenously labeled using radioiodination (Table IV). LDL measurements are similar to those obtained in a study of five postmenopausal women (23); large VLDL measurements are similar to those obtained in a study of seven healthy subjects, ages $22-48(9)$. To our knowledge, there is no single metabolic study of VLDL subfractions and LDL in normolipidemic young women that used radioidinated lipoproteins that would be directly comparable to the present study.

Metabolic measurements. OC users had significantly greater rates of VLDL apoB production compared to nonusers (Fig. 4): for large VLDL (Sf 60-400) it was 4.9 times higher ( $P$ $<0.01$ ) ; and for small VLDL (Sf 20-60) it was 3.4 times higher $(P<0.05)$. The mean production rates of unfractionated VLDL isolated by fixed angle ultracentrifugation were also significantly higher among OC users: $21 \mathrm{nmol} / \mathrm{kg}$ per d, vs. 11 $\mathrm{nmol} / \mathrm{kg}$ per $\mathrm{d}$ for nonusers $(P<0.05)$. There was no overlap between groups for large VLDL production rates. Exclusion of the subject who took the $\mathrm{OC}$ which contained ethynodiol diacetate did not alter our results.

In contrast, the two groups did not have significantly different FCR for large VLDL, small VLDL, and LDL (Fig. 4). Although the mean production rate of LDL was $15 \%$ higher in OC users, this difference was not statistically significant $(P$ $=0.77$ ).

\section{Discussion}

We found that women who use contemporary low dose oral contraceptives, which contain $0.035 \mathrm{mg}$ ethinyl estradiol, have significantly higher plasma levels of VLDL triglyceride, apoB, and cholesterol. We further found that these greater VLDL levels are due to increased VLDL production, and are not the result of reduced VLDL clearance. In particular, OC use has the greatest effect on large, triglyceride-rich VLDL, increasing its plasma concentration threefold, and production rate fivefold. The increases in small VLDL concentrations and production rates were statistically significant but smaller in magnitude

Table I. Characteristics of Oral Contraceptive Users and Nonusers

\begin{tabular}{|c|c|c|c|c|c|c|c|c|c|c|c|c|c|}
\hline \multirow[b]{2}{*}{ Subject } & \multicolumn{6}{|c|}{ OC Users } & \multicolumn{7}{|c|}{ OC Nonusers } \\
\hline & 1 & 2 & 3 & 4 & 5 & mean $\pm S D$ & 6 & 7 & 8 & 9 & 10 & 11 & mean $\pm \mathrm{SD}$ \\
\hline Age $(y r)$ & 24 & 23 & 22 & 22 & 23 & $23 \pm 1$ & 27 & 23 & 24 & 26 & 23 & 23 & $24 \pm 2$ \\
\hline Height $(\mathrm{cm})$ & 165 & 173 & 166 & 160 & 157 & $164 \pm 6$ & 167 & 163 & 157 & 149 & 164 & 165 & $161 \pm 7$ \\
\hline Weight $(k g)$ & 66.9 & 64.6 & 56.8 & 60.1 & 54.4 & $60.6 \pm 5.2$ & 68.1 & 56.6 & 50.5 & 53.1 & 60.5 & 71.6 & $60.1 \pm 8.4$ \\
\hline Quetelet's index* & 2.45 & 2.16 & 2.06 & 2.35 & 2.21 & $2.24 \pm 0.15$ & 2.44 & 2.13 & 2.05 & 2.39 & 2.25 & 2.62 & $2.31 \pm 0.21$ \\
\hline Exercise $(h / w k)$ & 4.0 & 5.0 & 3.0 & 2.0 & 6.0 & $4.0 \pm 1.6$ & 2.0 & 10.0 & 4.5 & 6.0 & 3.0 & 6.0 & $5.3 \pm 2.8$ \\
\hline \multicolumn{14}{|l|}{ Dietary intake } \\
\hline Calories per $\mathrm{d}$ & 1,313 & 2,558 & 2,702 & 1,936 & 2,033 & $2,110 \pm 550$ & 1,410 & 2,902 & 1,731 & 2,030 & 2,194 & 1,972 & $2,040 \pm 500$ \\
\hline Protein (\% calories) & 14 & 23 & 17 & 15 & 19 & $18 \pm 4$ & 16 & 16 & 21 & 18 & 15 & 20 & $18 \pm 2$ \\
\hline Fat (\% calories) & 33 & 28 & 26 & 18 & 17 & $24 \pm 7$ & 17 & 20 & 26 & 22 & 24 & 23 & $22 \pm 3$ \\
\hline Saturated & 12 & 10 & 9 & 6 & 5 & $8 \pm 3$ & 5 & 9 & 10 & 6 & 8 & 9 & $8 \pm 2$ \\
\hline Polyunsaturated & 7 & 6 & 5 & 4 & 4 & $5 \pm 1$ & 5 & 3 & 4 & 4 & 4 & 3 & $4 \pm 1$ \\
\hline Monounsaturated & 12 & 10 & 9 & 5 & 5 & $8 \pm 3$ & 6 & 7 & 9 & 7 & 8 & 8 & $8 \pm 1$ \\
\hline Carbohydrate (\% calories) & 48 & 50 & 55 & 71 & 67 & $58 \pm 10$ & 67 & 64 & 52 & 62 & 63 & 58 & $61 \pm 5$ \\
\hline Sucrose & 10 & 10 & 7 & 14 & 8 & $10 \pm 3$ & 11 & 16 & 13 & 9 & 11 & 9 & $12 \pm 3$ \\
\hline Cholesterol $(m g / d)$ & 163 & 327 & 250 & 57 & 167 & $193 \pm 102$ & 61 & 216 & 256 & 213 & 160 & 335 & $207 \pm 92$ \\
\hline Fiber $(g / d)$ & 14 & 28 & 28 & 23 & 44 & $27 \pm 11$ & 21 & 20 & 22 & 33 & 42 & 28 & $28 \pm 9$ \\
\hline Alcohol use $(g / d)$ & 4.6 & 2.9 & 12.6 & 1.1 & 3.9 & $5.0 \pm 4.4$ & 5.7 & 6.9 & 8.3 & 7.2 & 4.8 & 5.8 & $6.5 \pm 1.3$ \\
\hline
\end{tabular}

${ }^{*}$ (Weight $[\mathrm{kg}] /$ height $\left.[\mathrm{cm}]^{2}\right) \times 1,000$.

All differences not statistically significant. 
Table II. Lipoprotein Concentrations of Oral Contraceptive Users and Nonusers

\begin{tabular}{|c|c|c|c|c|c|c|c|c|c|c|c|c|c|}
\hline \multirow[b]{2}{*}{ Subject } & \multicolumn{6}{|c|}{ OC Users } & \multicolumn{7}{|c|}{ OC Nonusers } \\
\hline & 1 & 2 & 3 & 4 & 5 & mean $\pm S D$ & 6 & 7 & 8 & 9 & 10 & 11 & $\operatorname{mean} \pm \mathrm{SD}$ \\
\hline \multicolumn{14}{|c|}{ Cholesterol (mmol/liter) } \\
\hline Total & 3.79 & 3.91 & 4.18 & 3.56 & 3.63 & $3.81 \pm 0.25$ & 5.05 & 3.27 & 4.24 & 3.09 & 3.58 & 3.56 & $3.80 \pm 0.72$ \\
\hline HDL & 1.31 & 1.16 & 1.31 & 1.24 & 1.26 & $1.25 \pm 0.06$ & 1.83 & 1.05 & 1.26 & 1.11 & 0.88 & 1.19 & $1.22 \pm 0.33$ \\
\hline LDL & 2.14 & 2.53 & 2.65 & 2.11 & 2.22 & $2.33 \pm 0.25$ & 3.09 & 1.93 & 2.86 & 1.86 & 2.53 & 2.27 & $2.42 \pm 0.50$ \\
\hline VLDL & 0.34 & 0.23 & 0.21 & 0.21 & 0.21 & $0.24 \pm 0.06$ & 0.13 & 0.28 & 0.08 & 0.10 & 0.18 & 0.13 & $0.15 \pm 0.07^{*}$ \\
\hline \multicolumn{14}{|c|}{ Triglyceride (mmol/liter) } \\
\hline VLDL & 0.50 & 0.38 & 0.32 & 0.49 & 0.24 & $0.39 \pm 0.11$ & 0.15 & 0.41 & 0.11 & 0.19 & 0.34 & 0.18 & $0.23 \pm 0.12^{*}$ \\
\hline
\end{tabular}

Compared with OC users, ${ }^{*} P \leq 0.05$.

To convert values for cholesterol to milligrams per deciliter, multiply by 38.8 .

To convert values for triglyceride to milligrams per deciliter, multiply by 87.5 .

(2.2-fold and 3.4-fold, respectively). Thus, the mechanism by which oral contraceptives raise triglyceride levels appears to be fundamentally different from that of endogenous hypertriglyceridemia, although both are characterized by high concentrations of large VLDL. In many individuals with endogenous hypertriglyceridemia, the conversion of large VLDL to small VLDL is retarded (9). This impaired lipolysis prolongs the residence time of large VLDL, so that it may acquire cholesterol ester from HDL (24). Cholesterol ester-rich VLDL from normolipidemic (13) and hyperlipidemic persons (25) may be atherogenic, since it promotes cholesterol ester formation in macrophages. In addition, impaired VLDL catabolism may decrease the formation of HDL in the circulation and accelerate HDL catabolism, leading to lower HDL concentrations which in turn may promote atherogenesis. In marked contrast, VLDL catabolism appears to be unaffected by OC use. Normal VLDL catabolism in OC users may contribute to the normal
HDL levels and lack of cholesterol enrichment of VLDL. For these reasons, we speculate that the observed increase in triglycerides produced by $\mathrm{OC}$ would not contribute to atherosclerosis. Our observations may therefore offer a possible biochemical explanation for why long-term $\mathrm{OC}$ use does not appear to increase the risk of cardiovascular disease later in life, despite increased triglyceride levels (26).

The increase in VLDL production induced by OC's is most likely due to its estrogen component, ethinyl estradiol. Schaefer et al. (12) found that a high dose of ethinyl estradiol, $0.100 \mathrm{mg}$, elevated the VLDL-apoB levels of three premenopausal women by doubling the rate of VLDL apoB production, from 8.6 to $16.0 \mathrm{mg} / \mathrm{kg}$ per $\mathrm{d}$. This increase in VLDL production rates is comparable to that seen in the present study of ethinyl estradiol, $0.035 \mathrm{mg}: 6.7 \mathrm{mg} / \mathrm{kg}$ per $\mathrm{d}$ for $\mathrm{OC}$ nonusers, and $22.5 \mathrm{mg} / \mathrm{kg}$ per $\mathrm{d}$ for $\mathrm{OC}$ users (Fig. 3). In contrast, micronized estradiol $2 \mathrm{mg}$, a less potent estrogen dose than ethinyl estra-

Table III. Apolipoprotein B Metabolic Rates of Oral Contraceptive Users and Nonusers

\begin{tabular}{|c|c|c|c|c|c|c|c|c|c|c|c|c|c|}
\hline \multirow[b]{2}{*}{ Subject } & \multicolumn{6}{|c|}{ OC Users } & \multicolumn{7}{|c|}{ OC Nonusers } \\
\hline & 1 & 2 & 3 & 4 & 5 & mean $\pm \mathrm{SD}$ & 6 & 7 & 8 & 9 & 10 & 11 & mean $\pm \mathrm{SD}$ \\
\hline \multicolumn{14}{|c|}{$\operatorname{LDL}(1.019<d<1.063)$} \\
\hline $\begin{array}{c}\text { Concentration } \\
(\text { nmol/liter })\end{array}$ & 940 & 1,190 & 1,470 & 1,160 & 1,080 & $1,170 \pm 200$ & 1,670 & 1,040 & 1,180 & 780 & 1,220 & 830 & $1,120 \pm 320$ \\
\hline $\begin{array}{l}\text { Production rate } \\
\quad(n m o l / k g \text { per } d)\end{array}$ & 17.4 & 23.0 & 24.3 & 16.7 & 22.8 & $20.8 \pm 3.5$ & 33.3 & 10.3 & 21.0 & 16.3 & 11.0 & 13.6 & $17.6 \pm 8.6$ \\
\hline FCR (pool/d) & 0.43 & 0.45 & 0.37 & 0.32 & 0.49 & $0.41 \pm 0.07$ & 0.45 & 0.23 & 0.42 & 0.48 & 0.21 & 0.38 & $0.36 \pm 0.11$ \\
\hline \multicolumn{14}{|c|}{ Large VLDL (Sf 60-400) } \\
\hline $\begin{array}{c}\text { Concentration } \\
(\text { nmol/liter })\end{array}$ & 23.9 & 35.1 & 8.3 & 25.3 & 8.3 & $20.2 \pm 12.0$ & 4.3 & 17.5 & 1.3 & 3.1 & 10.5 & 3.6 & $6.7 \pm 6.2^{*}$ \\
\hline $\begin{array}{l}\text { Production rate } \\
\quad(\text { nmol/kg per } d)\end{array}$ & 12.3 & 23.9 & 17.6 & 17.4 & 12.5 & $16.7 \pm 4.7$ & 3.0 & 3.9 & 1.3 & 2.8 & 5.3 & 4.1 & $3.4 \pm 1.4^{\ddagger}$ \\
\hline FCR $(p o o l / d)$ & 12.2 & 18.7 & 24.0 & 15.6 & 26.4 & $19.4 \pm 5.9$ & 15.6 & 10.8 & 22.8 & 22.2 & 11.5 & 26.4 & $18.2 \pm 6.5$ \\
\hline \multicolumn{14}{|c|}{ Small VLDL (Sf 20-60) } \\
\hline $\begin{array}{c}\text { Concentration } \\
(\text { nmol/liter })\end{array}$ & 25.3 & 33.7 & 42.7 & 52.5 & 29.1 & $36.7 \pm 11.0$ & 14.5 & 48.9 & 4.2 & 7.4 & 21.6 & 3.6 & $16.7 \pm 17.1^{*}$ \\
\hline $\begin{array}{l}\text { Production rate } \\
\quad(n m o l / k g \text { per } d)\end{array}$ & 14.5 & 28.9 & 25.3 & 32.2 & 11.3 & $22.5 \pm 9.1$ & 7.0 & 7.8 & 4.2 & 4.1 & 12.1 & 5.2 & $6.7 \pm 3.0^{5}$ \\
\hline FCR $(p o o l / d)$ & 13.7 & 20.4 & 13.4 & 13.9 & 13.8 & $15.1 \pm 3.0$ & 11.0 & 7.7 & 24.0 & 12.9 & 12.7 & 33.6 & $17.0 \pm 9.8$ \\
\hline
\end{tabular}

Compared with $O C$ users, ${ }^{*} P \leq 0.05,{ }^{8} P \leq 0.01,{ }^{\ddagger} P \leq 0.005$.

To convert values for apoB concentrations to milligrams per deciliter, divide by 18.1 .

To convert values for apoB production rates to milligrams per kilogram per day, divide by 1.81 . 
diol, $0.035 \mathrm{mg}$, has been reported to increase large VLDL production rates of healthy postmenopausal women only 1.8 -fold (3), as compared to the fivefold higher rates seen in the present study. Thus, lower doses of estrogen may increase VLDL production rates in a dose-dependent fashion, until a biologic maximum is reached, beyond which no further increases are possible.

The present study did not find OC's to increase VLDL catabolic rates. Such an increase might be expected, based on the work of Kissebah et al. (11) who studied women using OC containing $0.050 \mathrm{mg}$ ethinyl estradiol with varying progestins. They found that VLDL triglyceride levels were twofold higher in OC users due to both twofold higher production rates and $45 \%$ higher catabolic rates. They attributed the latter effect to the progestin component of the $\mathrm{OC}$, since their comparison group of estrogen-only users did not show increased rates of VLDL catabolism. That the present study did not find an increase in VLDL catabolic rates may be due to the lower dose of progestins currently used. Alternatively, a modest effect of the progestin component on FCR (in contrast to the several-fold effect of estrogen on VLDL production) might not have been detected, since this study had sufficient statistical power (80\%) to detect changes in VLDL FCR of only $50 \%$ or more.

OC users and nonusers had similar rates of LDL production and catabolism, in contrast to the marked differences in their rates of VLDL metabolism. This study had adequate statistical power $(80 \%)$ to detect a change in LDL FCR of $27 \%$ or greater. However, increases in LDL FCR of this magnitude might be expected, since $2 \mathrm{mg}$ micronized estradiol (which is far less potent than ethinyl estradiol) given to postmenopausal women increased the FCR of LDL by $38 \%$, from 0.24 to 0.33 $\mathrm{pool} / \mathrm{d}(3)$. Two explanations for the apparent lack of effect of OC's on LDL metabolism may be offered: $(a)$ An increase in LDL catabolism induced by ethinyl estradiol may have been negated by the progestin component of the OC. $(b)$ Young women, having relatively high LDL FCR's, may be at a "biologic maximum" for LDL catabolism (possibly $0.45 \mathrm{pool} / \mathrm{d}$ ) beyond which no additional increases with $\mathrm{OC}$ use are possible.

Table IV. Comparison of Metabolic Data Obtained by Endogenous Stable Isotope Labeling (Present Study) and by Exogenous Radioiodination

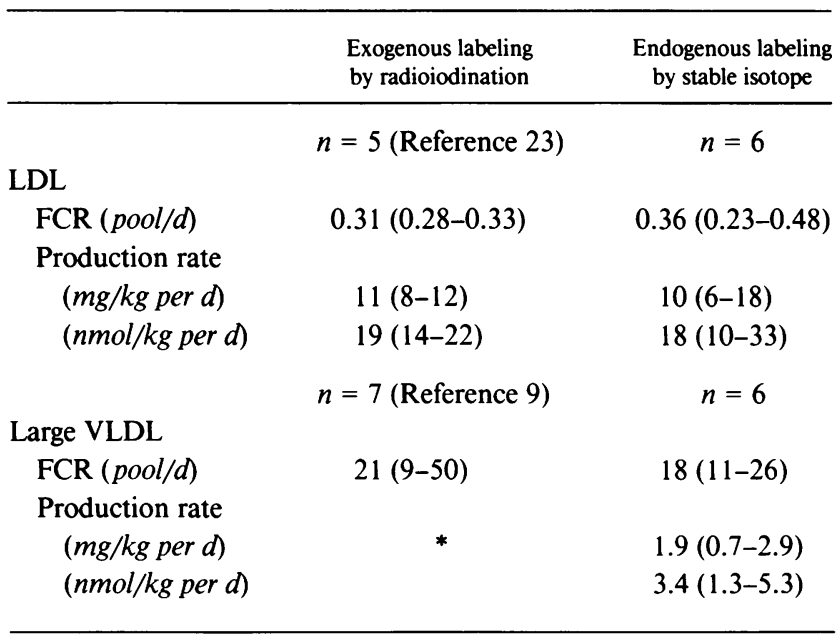

Values are listed as means (range).

* Not reported by investigator.
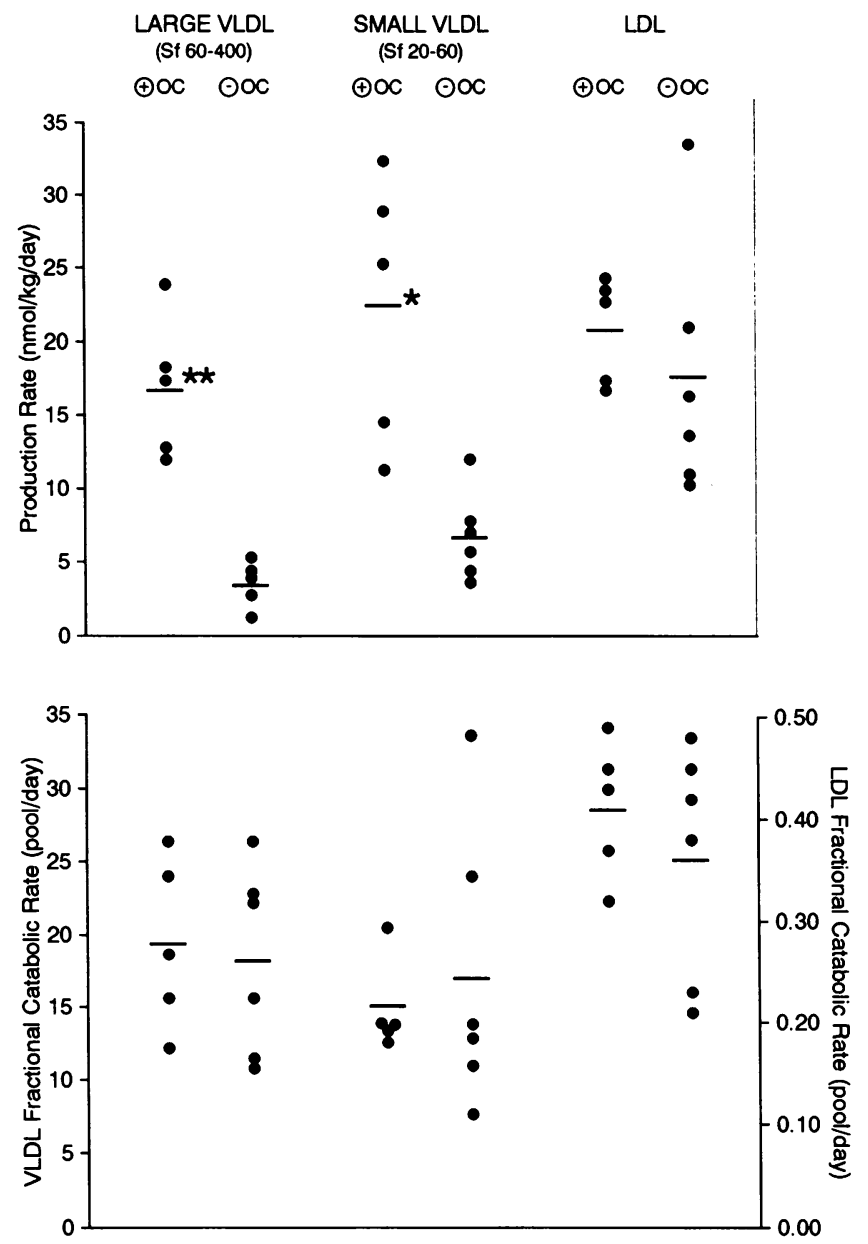

Figure 4. The production rates $(\mathrm{nmol} / \mathrm{kg}$ per $\mathrm{d})$ and fractional catabolic rates (pool/d) of large VLDL apoB (Sf 60-400), small VLDL apoB (Sf 20-60), and LDL apoB ( $d=1.019-1.063)$, for oral contraceptive users $(+O C)$ and nonusers $(-O C)$. Each point shows the data of one patient. Horizontal bars show the means of each group. Users vs. nonusers, ${ }^{*} P<0.01$ and ${ }^{* *} P<0.005$.

\section{Acknowledgments}

We thank Dr. Dennis Cryer for advice on using stable isotopes, Helena Li for expert technical assistance in the lipid laboratory, and the dedicated subjects in this study.

This work was supported by a grant (RO1HL-34980) from the National Heart, Lung, and Blood Institute, and a Clinical Research Center grant (MO1-RR2635) from the National Institutes of Health. Dr. Walsh is a recipient of a Clinician Scientist Award in Lipoprotein Metabolism from the American Heart Association/Parke Davis. Dr. Sacks is the recipient of an American Heart Association Established Investigator Award.

\section{References}

1. Wahl, R., C. Walden, R. Knopp, J. Hoover, R. Wallace, G. Heiss, and B. Rifkind. 1983. Effect of estrogen/progestin potency on lipid/lipoprotein cholesterol. N. Engl. J. Med. 308:862-867.

2. Carlson, L. A., I. E. Bottiger, and P. E. Ahfeldt. 1979. Risk factors for myocardial infarction in the Stockholm prospective study: a 14-year follow-up focusing on the role of plasma triglyceride and cholesterol. Acta Med. Scand. 206:351-360.

3. Walsh, B. W., I. Schiff, B. Rosner, L. Greenberg, V. Ravnikar, and F. Sacks. 1991. Effects of postmenopausal estrogen replacement on the concentrations and metabolism of plasma lipoproteins. N. Engl. J. Med. 325:1196-2004. 
4. Taskinen, M., E. A. Nikkila, M. Valimaki, T. Sane, T. Kuusi, Y. A. Kesaniemi, and R. Ylikahri. 1987. Alcohol-induced changes in serum lipoproteins and in their metabolism. Am. Heart J. 2:458-464.

5. Angelin, B., K. Einarsson, K. Hellstrom, and B. Leijd. 1978. Effects of cholestyramine and chenodeoxycholic acid on the metabolism of endogenous triglyceride in hyperlipoproteinemia. J. Lipid Res. 19:1017-1024.

6. Stampfer, M. J., G. A. Colditz, W. C. Willett, J. E. Manson, B. Rosner, F. E. Speizer, and C. H. Hennekens. 1991. Postmenopausal estrogen therapy and cardiovascular disease. N. Engl. J. Med. 325:756-762.

7. Moore, R. D., and T. A. Pearson. 1986. Moderate alcohol consumption and coronary artery disease: a review. Medicine (Baltimore). 65:242-267.

8. Lipid Research Clinics Program. 1984. The Lipid Research Clinics coronary primary prevention trial results. JAMA (J. Am. Med. Assoc.). 251:351-364.

9. Packard, C. J., A. Munro, A. R. Lorimer, A. M. Gotto, and J. Shepherd. 1984. Metabolism of apolipoprotein B in large triglyceride-rich very low density lipoproteins of normal and hypertriglyceridemic subjects. J. Clin. Invest. 74:2171-2192.

10. Brunzell, J. D., H. G. Schrott, A. G. Motulsky, and E. L. Bierman. 1976. Myocardial infarction in the familial forms of hypertriglyceridemia. Metab. Clin. Exp. 25:313-320.

11. Kissebah, A. H., P. Harrigan, and V. Wynn. 1973. Mechanism of hypertriglyceridaemia associated with contraceptive steroids. Horm. Metab. Res. 5:184-190.

12. Schaefer, E. J., D. M. Foster, L. A. Zech, F. T. Lindgren, H. B. Brewer, Jr., and R. I. Levy. 1983. The effects of estrogen administration on plasma lipoprotein metabolism in premenopausal females. J. Clin. Endocrinol. \& Metab. 57:262-267.

13. Sacks, F. M., and J. L. Breslow. 1987. Very low density lipoproteins stimulate cholesteryl ester formation in U937 macrophages. Heterogeneity and biologic variation among normal humans. Arteriosclerosis. 7:35-46.

14. Gianturco, S. H., W. A. Bradley, A. M. Gotto, Jr., J. D. Morrisett, and D. L. Peavy. 1982. Hypertriglyceridemic very low density lipoproteins induce triglyceride synthesis and accumulation in mouse peritoneal macrophages. $J$. Clin. Invest. 70:168-178.

15. Willett, W. C., L. Sampson, M. L. Browne, M. J. Stampfer, B. Rosner,
C. H. Hennekens, and F. E. Speizer. 1988. The use of a self-administered questionnaire to assess diet four years in the past. Am. J. Epidemiol. 127:188-199.

16. Lindgren, F. T., L. C. Jensen, and F. T. Hatch. The isolation and quantitative analysis of serum lipoproteins. In Blood Lipids and Lipoproteins. G. J. Nelson, editor. John Wiley \& Sons, Inc., New York. 181-274.

17. Havel, R. J., H. A. Eder, and J. H. Bragdon. 1955. The distribution and chemical composition of ultracentrifugally separated lipoproteins in human serum. J. Clin. Invest. 34:1345-1353.

18. Bachorik, P. S., and J. J. Albers. 1986. Precipitation methods for quantification of lipoproteins. Methods Enzymol. 129:78-100.

19. Warnick G. R. 1986. Enzymatic methods for quantification of lipoprotein lipids. Methods Enzymol. 129:101-123.

20. Egusa, G., D. W. Brady, S. M. Grundy, and B. V. Howard. 1983. Isopropanol precipitation method for metabolic studies of very low density lipoprotein and low density lipoprotein apolipoprotein B. J. Lipid Res. 24:1261.

21. Cryer, D. R., T. Matsushima, J. B. Marsh, M. Yudkoff, P. M. Coates, and J. A. Cortner. 1986. Direct measurement of apolipoprotein B synthesis in human very low density lipoprotein using stable isotopes and mass spectrometry. J. Lipid Res. 27:508-516.

22. Zilversmit, D. B. 1960. The design and analysis of isotope experiments. Am. J. Med. 29:832-848.

23. Wolfe, B. M., and M. W. Huff. 1989. Effects of combined estrogen and progestin administration on plasma lipoprotein metabolism in postmenopausal women. J. Clin. Invest. 83:40-45.

24. Tall, A., E. Granot, R. Brocia, I. Tabas, C. Hesler, K. Williams, and M. Denke. 1987. Accelerated transfer of cholesteryl esters in dyslipidemic plasma: role of cholesteryl ester transfer protein. J. Clin. Invest. 79:1217-1225.

25. Bersot, T. P., T. L. Innerarity, R. W. Mahley, and R. J. Havel. 1983. Cholesteryl ester accumulation in mouse peritoneal macrophages induced by beta-migrating very low density lipoproteins from patients with atypical dysbetalipoproteinemia. J. Clin. Invest. 72:1024-1033.

26. Stampfer, M. J., W. C. Willett, G. A. Colditz, F. E. Speizer, and C. H. Hennekens. 1988. A prospective study of past use of oral contraceptive agents and risk of cardiovascular diseases. N. Engl. J. Med. 319:1313-1317. 